\title{
Civilisations
}

Revue internationale d'anthropologie et de sciences

humaines

$41 \mid 1993$

Mélanges Pierre Salmon II

\section{Quelques problèmes de mise en valeur du bassin du Sénégal}

Esquisse historique à travers l'analyse de la tentative de colonisation agricole française du Delta du fleuve Sénégal

Amadou M. Camara

\section{(2) OpenEdition}

12 Journals

\section{Édition électronique}

URL : http://journals.openedition.org/civilisations/1719

DOI : 10.4000/civilisations. 1719

ISSN : 2032-0442

Éditeur

Institut de sociologie de l'Université Libre de Bruxelles

\section{Édition imprimée}

Date de publication : 1 septembre 1993

Pagination : 337-345

ISBN : 2-87263-094-5

ISSN : 0009-8140

\section{Référence électronique}

Amadou M. Camara, «Quelques problèmes de mise en valeur du bassin du Sénégal », Civilisations [En ligne], 41 | 1993, mis en ligne le 30 juillet 2009, consulté le 10 décembre 2020. URL : http://

journals.openedition.org/civilisations/1719; DOI : https://doi.org/10.4000/civilisations.1719

Ce document a été généré automatiquement le 10 décembre 2020.

(c) Tous droits réservés 


\section{Quelques problèmes de mise en valeur du bassin du Sénégal}

Esquisse historique à travers l'analyse de la tentative de colonisation agricole française du Delta du fleuve Sénégal

Amadou M. Camara

1 D'importants projets de mise en valeur sont en cours d'exécution dans les bassins des grands fleuves d'Afrique, comme pour ressusciter les civilisations qui y ont fleuri au cours des âges (civilisation de l'Egypte ancienne dans la vallée du Nil, civilisations du Soudan médiéval sur les boucles divergentes du Sénégal et du Niger...). Mais les tentatives de rénovation de ces espaces, ne sont, dans la plupart des cas, qu'une sorte de "remake" d'une idée née avec la pénétration européenne. La mise en valeur actuelle du bassin du fleuve Sénégal en est un exemple.

2 En effet, des tentatives de colonisation agricole du delta aux périmètres irrigués actuels de la SAED, de la SONADER ou de l'OVSTM ${ }^{1}$, en passant par les jardins d'essai (de Saldé, de Diorbivol...), seules les motivations ont dû changer. L'objectif de faire du bassin d'abord une tête de pont prospère, puis un des greniers de la sous-région, est resté intact; les stratégies aussi, mais avec des fortunes diverses, riches d'enseignement pour le présent et pour le futur.

3 Les formes actuelles de mise en valeur, avec leur cortège de problèmes ne sont ainsi que l'aboutissement d'un processus, la maturation d'un projet qui aura traversé près de deux siècles. A la lumière de l'expérience de colonisation agricole du delta, peut-on comprendre quelques problèmes de mise en valeur actuelle de la vallée du fleuve?

\section{Naissance, objectifs et champ d'application d'un projet}

\section{La naissance de l'idée de mise en valeur du bassin du fleuve}

D'une manière générale, les cours d'eau ont joué un rôle prépondérant dans l'exploration, la connaissance et la conquête du continent africain par l'Europe. La présence européenne sur les côtes africaines s'est d'abord manifestée sur les embouchures des 
cours d'eau. Sur celle du Sénégal, elle remonte à 1450 avec le Portugais Cada Mosto. Précédant de peu, la découverte de l'Amérique, elle ouvre l'entreprise, "non préméditée" (est-il utile de le rappeler ?) de plus de trois siècles de commerce triangulaire. Le congrès de Vienne abolit la traite en 1815. La Grande-Bretagne supprime l'esclavage dans son empire et "monte la garde sur les trois mers autour de l'Afrique"2. Cette nouvelle donne somme les puissances européennes de s'adapter.

Ayant mis un terme à la traite en 1848, sous le Gouvernement provisoire, la France cherche un substitut à l'approvisionnement des industries de la Métropole. Elle décide alors de passer du comptoir au continent. Elle en est d'autant plus tentée que les militaires l'y poussent depuis que le Colonel Schmaltz, après un voyage le long du fleuve en 1817, avait vanté le fleuve Sénégal en le comparant au Gange et dont les rives, disait-il, s'accommoderaient aussi bien de la canne à sucre, de l'indigotier que du coton, ainsi que de "toutes les cultures qu'on y voudra".

Le colonel Schmaltz confortait ainsi le plan de colonisation agricole du Sénégal que le Baron Portai avait mis au point à la demande de Louis XVIII. Celui-ci ne faisait que compléter les plans déjà conçus pour la Guyane et pour Madagascar. Il fallut attendre 1821 pour que le Baron Roger, successeur de Schmaltz, mit en oeuvre ce plan de colonisation agricole.

\section{Les objectifs du plan de colonisation agricole}

7 A travers la colonisation agricole, le plan visait à long terme la création d'une colonie de peuplement. En effet, il avait été question, dans le plan Portai, de faire venir des colons européens à qui seraient attribuées des terres qu'ils mettraient en valeur avec de la maind'oeuvre indigène.

Mais dans l'immédiat, l'objectif fut de trouver une stratégie de reconversion face au "désordre" que l'abolition de la traite ne manquerait pas d'engendrer pour l'économie française. C. Schefer ${ }^{3}$ a bien résumé cette intention : "à défaut de pouvoir transporter les esclaves là où se trouvait le travail, on décidait de faire venir le travail là où il y avait des ouvriers à bon marché". On sait que cette main-d'oeuvre bon marché fut progressivement transformée en main-d'oeuvre servile par l'instauration plus tard du travail forcé dans les colonies $^{4}$.

Mais si l'entreprise était justifiée aux yeux de ses promoteurs et ses objectifs clairement définis, sa réalisation n'en posait pas moins quelques problèmes parmi lesquels celui du cadre géographique expérimental.

\section{Le champ d'application}

Nommé gouverneur en 1816, le Colonel Schmaltz avait jeté son dévolu sur le delta du fleuve pour la matérialisation de l'idée. Au plan pédologique ce n'était certainement pas le meilleur choix : la zone deltaïque souffrait en effet jusqu'à une période récente encore de la remontée périodique de la langue salée loin à l'intérieur du fleuve (jusqu'à Boghé parfois, à plus de $300 \mathrm{~km}$ de l'embouchure). Elle se caractérise ainsi par la nature halomorphe de ses sols, c'est-à-dire "des sols dont l'évolution est dominée par la présence de sels solubles dont la teneur élevée limite leur productivité et provoque une modification importante de la végétation"5. La moyenne vallée aux sols plus riches et à la plaine alluviale plus étendue se prêtait sans doute mieux à une telle entreprise. 
11 Des considérations géostratégiques ont dû prévaloir dans le choix de ce site : la proximité du comptoir de Saint- Louis, la navigabilité du fleuve à cet endroit en toutes saisons...

12 Mais l'option n'était pas politiquement sans risques: le puissant royaume du Walo continuait à prospérer dans le delta du fleuve depuis le $\mathrm{XVI}^{\mathrm{e}}$ siècle. Sa prospérité était telle, qu'il n'avait cessé de faire l'objet de convoitises de la part de ses voisins du Nord: les tribus maures Trarza et Brakna. C'est en exploitant à fond l'insécurité qui pesait sur la région ainsi que les querelles dynastiques à l'intérieur du royaume que le Baron Roger, ayant succédé au colonel Schmaltz en 1821, mettra en oeuvre le plan de colonisation agricole.

\section{La mise en oeuvre du plan de colonisation agricole}

13 Dès sa prise de fonction, le Baron Roger créa un jardin expérimental sur le site de l'actuelle commune de Richard-Toll à la confluence entre la Taouey et le fleuve Sénagal. Cette ville doit d'ailleurs son nom au jardinier-pépiniériste du nom de Richard à qui le Baron avait confié l'exécution du projet en $1822^{6}$.

14 Le jardinier cibla les trois domaines d'action suivants : la réalisation d'aménagements hydroagricoles, la recherche agronomique et l'expérimentation à grande échelle.

\section{Les aménagements hydroagricoles}

De 1822 à 1824, Richard s'attacha à mettre en oeuvre des techniques d'aménagement et d'irrigation en s'inspirant des expériences concluantes menées dans ces domaines en Algérie. Les labours profonds à la charrue, l'irrigation à la noria (sortes de bascules servant à faire monter l'eau) ainsi que le bassinage et l'endiguement sont en effet des techniques d'aménagements hydroagricoles déjà fortement éprouvées au Magreb. Seuls le défrichement et le déssouchage, avec des instruments traditionnels comme la hache, le coupe-coupe, la daba, étaient relativement bien connus par la main-d'oeuvre locale.

16 Avec ce système d'aménagement et de mise en valeur, une technologie nouvelle venait ainsi de faire irruption dans la vallée du Sénégal. Elle ne cessera de s'adapter aux conditions locales au point d'inspirer les expériences actuelles de culture irriguée.

\section{L'exploitation}

L'originalité de l'exploitation réside dans la cohabitation de cultures locales et de cultures importées à titre expérimental.

ultures locales comprenaient des céréales, des fruits et des légumes. La culture céréalière était destinée à la consommation locale. Elle était constituée pour l'essentiel d'une variété de riz semblable à une espèce naturelle poussant localement dans les mares et que les populations appelaient de ce fait même "riz de mare". Il n'entrait dans leur alimentation qu'exceptionnellement pendant les périodes de soudure. Il apparaît donc clairement que cette culture était destinée aux besoins presqu'exclusifs des colons français.

19 Les fruits et légumes locaux cultivés se composaient de melons, de piments, de tomates et de patates... 
20 Les cultures importées comprenaient quant à elles essentiellement des cultures industrielles tournées vers la satisfaction des besoins de la Métropole. Le coton s'y taillait la part du lion avec l'expérimentation d'une multitude de variétés : coton à fibres courtes importé d'Egypte, coton herbacé de Chandernagor... La culture du coton était associée à celles des plantes tinctoriales et à l'élevage du ver à soie sur mûrier. Même l'élevage de cochenilles sur nopals fut tenté sans grand succès compte tenu des conditions écologiques locales inadaptées à leur développement (chaleur, humidité...). Mais les cultures industrielles comprenaient plusieurs variétés de fruits : figuiers, vignes, oliviers, orangers comme espèces méditerranéennes ainsi que l'ananas et le bananier importés des Iles du Cap-Vert et le caféier des Antilles. Assurément, le projet ne manquait pas d'ambitions! Les résultats furent cependant inégaux dans un premier temps et franchement mauvais par la suite.

\section{Le bilan de l'expérience et son impact sur la mise en valeur actuelle du fleuve}

\section{L'extension du projet et ses résultats}

Les résultats des premières années de l'expérience furent assez mitigés. Les expériences de cultures industrielles furent dans l'ensemble concluantes. Les rendements du coton avoisinèrent et dépassèrent même 1 tonne à l'hectare. Les plantes tinctoriales répondirent comme par écho à cette réussite. Des fabriques se multiplièrent alors à SaintLouis entre 1823 et 1824 : machines à égrener, ateliers de tissage, indigoteries...

Les légumes cultivés en variétés locales comme en variétés importées connurent également un succès. Par contre, l'échec fut cuisant pour les céréales, en particulier le riz, et pour les fruits exotiques. Les difficultés de désherbage eurent raison de la tentative de domestication du riz rouge. Les fruits importés quant à eux ne s'acclimatèrent point.

Ces résultats étaient jugés malgré tout suffisants pour justifier l'extension du projet.

Les superficies du jardin furent étendues à tel point qu'en 1826, plus de 6.500 hectares avaient été aménagés dans le delta. On fit venir des colons européens à qui l'on concéda des exploitations individuelles dans des conditions de cessions de terres en porte à faux avec les coutumes locales. Des primes de production furent instituées. Une "Société d'agriculture" fut créée pour la recherche et la vulgarisation variétales. Le Baron décida d'étendre le projet dans toute la vallée avec la création des jardins de Faj et de Dagana. Des extensions furent même prévues à Demet, à Saldé et à Diorbivol dans la moyennevallée. Elles resteront cependant lettre-morte car l'expérience ne survécut point au départ du Baron en 1826.

\section{Les causes et les enseignements d'un échec}

Plusieurs causes ont été invoquées pour expliquer l'échec de l'expérience.

Gerbidon, un enquêteur que la France avait dépêché sur les lieux, insista dans son rapport sur des causes écologiques : salinité des sols, effets néfastes de l'harmattan (vent chaud et sec de composante est et de trajectoire continentale soufflant en saison sèche) et agronomiques : mauvais calendrier cultural, labours trop profonds... 
Raffenel, un voyageur français dans la région fut frappé par l'insécurité qui y régnait entre 1827 et 1830 .

Boubacar Barry fut plus prolifique en ramassant ainsi qu'il suit, les causes à la fois de natures politique, économique et sociale: "la pression des peuples voisins à laquelle s'ajoutaient les difficultés de cession des terres, l'emploi d'une main-d'oeuvre réticente et enfin la résistance de l'ancien commerce des comptoirs de Saint-Louis (dont les tenants alimentaient les hostilités par un commerce lucratif d'armes avec les autochtones) ont pesé d'un lourd poids sur la balance de l'échec".

Les causes pédo-climatiques et techniques avancées par Gerbidon résistent cependant très peu à l'analyse. Si ces facteurs peuvent justifier l'échec de certaines tentatives d'acclimatation notamment pour les fruits, ils ont, à contrario, stimulé plusieurs autres spéculations (légumes, cultures industrielles...). Du reste, les résultats obtenus entre 1822 et 1826 ne sauraient s'expliquer par le seul volontarisme du jardinier-pépiniériste. Les résultats obtenus par la suite dans le delta, bien après les tentatives de colonisation agricole, incitent à nuancer considérablement les conclusions de l'enquêteur.

Quant à l'insécurité rapportée par Raffenel, elle était bien réelle. Mais le chroniqueur reste bien muet sur ses causes. La plus profonde reste la présence du projet lui-même une sorte de kyste sur le tissu socio-économique et politique local.

Parmi les facteurs proposés par Barry, un paraitt tenace puisqu'ayant traverssé les siècles et fait échouer plus d'un projet : le problème foncier.

De tous les problèmes qui se posent aujourd'hui à la politique d'aménagement de la vallée (qu'on appelle ici "l'après-barrages") on peut dire sans risque de se tromper que celui de la terre est le plus aigu. Le rapport de l'homme à la terre dans le bassin du Sénégal constitue le socle sur lequel peuvent se superposer en concordance ou en discordance tous les problèmes de développement dans leurs dimensions politiques, économiques et techniques. Historiquement, l'échec de la tentative de colonisation agricole du delta, éclaire sous certains aspects et d'une certaine manière les difficultés actuelles de modernisation. Dès 1938, la M.A.S. (Mission d'aménagement du Sénagal) butta sur la question foncière. Entre 1960 et 1962, l'OAD (Organisation autonome du Delta), et l'OAV (Organisation autonome de la Vallée) échouèrent sur la même question.

Les procès des "saboteurs de digues" de protection des cuvettes retentissent encore dans plusieurs localités de la vallée. Les casiers rizicoles actuellement aménagés sous les auspices de la SAED, de la SONADER et de l'OVSTM vacillent sous les coups de boutoir des propriétaires terriens. Le conflit qui a éclaté le 9 avril 1989 entre le Sénégal et la Mauritanie trouve son orgine dans le problème foncier.

Force est de constater que ni les expéditions militaires de la garnison de Saint-Louis que le Baron Roger organisait dès 1821 pour soutenir son projet face à l'hostilité des populations locales, ni les lois domaniales post-indépendances n'ont pu venir à bout du régime foncier traditionnel.

Sans doute, faut-il en arriver à la codification d'un régime foncier spécifique à la vallée, c'est-à-dire adapté aux réalités sociales et historiques locales (ce que le socio-linguiste sénégalais Pathè Diagne appelle "droit riverain"), pour surmonter une des plus grosses difficultés auxquelles se heurte l'aménagement de cette région! 


\section{NOTES}

1. Organismes ayant en charge le développement de la culture irriguée dans le bassin du Sénagal :

- SAED : Société d'aménagement et d'exploitation des terres du delta et des vallées du Sénégal et de la Falémé (Sénégal)

- SONADER : Société Nationale pour le développement rural (Mauritanie)

- OVSTM : Opération Vallées du Sénégal, Térékolé - Magui (Mali).

2. KI-ZERBO Joseph : "Histoire de l'Afrique noire", Hatier 1973.

3. KI-ZERBO, op.cit.

4. FALL, Babacar "Le travail forcé en Afrique noire 1900-1946", Paris, Khartala, 1992.

5. Organisation pour la Mise en Valeur du Fleuve Sénégal (OMVS) : "Etude socio-économique du bassin du fleuve Sénégal. Partie C. L'introduction de la culture irriguée", 1980.

6. Richard-Toll : nom wolof signifiant littéralement: le champ de Richard. C'est ainsi que les populations locales désignaient le jardin du pépiniériste.

7. BARRY, Boubacar : "Le Sénégal avant la conquête - Le royaume du Walo" Maspero, 1972.

\section{RÉSUMÉS}

Large development projects are in progress in the more important river basins of Africa. Renovation attempts in these areas are, for the most part, re-makes of an idea which came to Africa with the Europeans. The development of the Senegal river basin is an example of this.

Whether now or in the colonial era, the objectives of making the Senegal river basin a prosperous beachhead, and one of the sub-regional breadbaskets have remained constant as have the strategies involved although producing different outcomes which provide rich lessons for the present and the future. Thus, we can analyse the attempt at agricultural colonisation, started in Senegal by baron Roger with the creation in 1822, of an experimental garden on the present site of the district of Richard Toll.

In the light of experience of agricultural colonisation of the delta, we can understand some of the present problems of the development of the reiver valley.

\section{AUTEUR}

\section{AMADOU M. CAMARA}

Ecole normale supérieure - Dakar - Sénégal 